\title{
Modal Structuralism and Theism
}

\author{
Silvia Jonas
}

September 5, 2017

\begin{abstract}
Drawing an analogy between modal structuralism about mathematics and theism, I offer a structuralist account that implicitly defines theism in terms of three basic relations: logical and metaphysical priority, and epistemic superiority. On this view, statements like 'God is omniscient' have a hypothetical and a categorical component. The hypothetical component provides a translation pattern according to which statements in theistic language are converted into statements of second-order modal logic. The categorical component asserts the logical possibility of the theism structure on the basis of uncontroversial facts about the physical world. This structuralist reading of theism preserves objective truth-values for theistic statements while remaining neutral on the question of ontology. Thus, it offers a way of understanding theism to which a naturalist cannot object, and it accommodates the fact that religious belief, for many theists, is an essentially relational matter ${ }^{1}$
\end{abstract}

\section{Introduction}

Theism is not popular among philosophers ${ }^{2}$ There are a number of reasons for this, but the most important one is certainly that the empirical sciences have taken over many of the explanatory roles that used to be fulfilled by the concept of God. Assuming the existence of an all-knowing and all-powerful being is no longer needed in order to explain nature in all its complexity: physics, astronomy, chemistry, meteorology, biology, and so forth offer not only explanations for the vast majority of observable phenomena, but also theories and models that allow their precise prediction. Naturalism is the philosophical position that pays homage to this stunning success of the sciences by considering only those philosophical positions viable that are, in some vaguely defined sense, 'consistent' with them.

\footnotetext{
${ }^{1}$ This article is forthcoming in Fiona Ellis, New Models of Religious Understanding, Oxford University Press.

${ }^{2}$ Not so among non-philosophers: According to the Encyclopaedia Britannica, only $2 \%$ of the world's population self-identify as atheists, a figure that decreased on average by $0.17 \%$ per year between 2000 and 2010. Source: https://www.britannica.com/topic/religion-YearIn-Review-2010/Worldwide-Adherents-of-All-Religions . However, the distribution of theism and atheism differs, of course, from country to country. According to the Global Index of Religion and Atheism, atheists are in the majority, for example, in Scandinavia, Germany, and China, whereas in almost all African countries, less than $10 \%$ of the population self-identify as atheists. Source: https://web.archive.org/web/20121016062403/http://redcresearch.ie/wpcontent/uploads/2012/08/RED-C-press-release-Religion-and-Atheism-25-7-12.pdf
} 
It is easy to see why traditional monotheistic interpretations of theism appear to be in tension with the natural sciences: the properties classically ascribed to God are incompatible with the scientifically defined preconditions for having such properties. For example, biological, neurological, and medical evidence seems to indicate very clearly that consciousness, identity, and person-hood require some kind of underlying physical structure, which stands in contradiction to the classical interpretation of God as an immaterial yet conscious person. Also the idea of a being that exerts causal influence on the physical world (for example by performing miracles that breach the laws of nature) without being physical itself is scientifically hard to maintain, and has only minimal appeal in light of the science's "extraordinarily rich explanatory structure, worked out in the crucible of a rigorously constrained methodology, and meticulously tested against a formidable range of observational evidence." 3

However, more than one conclusion can be drawn from the apparent incompatibility of science with classical interpretations of God and theism. The first one is to reject theism; but this is an unacceptable route for theists. The second one is to reject naturalism; but this is an unacceptable route for many philosophers. A third one is to argue for an interpretation of naturalism that doesn't preclude theism ${ }^{4}$ A fourth one is to argue for an interpretation of theism that doesn't preclude naturalism. This is the route I explore in this paper.

I argue that we need to develop new ways of theorizing about God and theism that are compatible with naturalism $\sqrt[5]{ }$ and I demonstrate what such a way could look like. Drawing an analogy between mathematical realism and theism, I offer an account that treats God like modal structuralists treat numbers. More precisely, I argue that, rather than trying to settle questions of ontology, theists should focus on the structural relations that define theistic belief (such as the logical priority relation implicit in theistic concepts like 'sin', 'revelation', or 'prophet'; the metaphysical priority relation implicit in the story of divine creation and in characterizations of God as omnipotent; and the epistemic priority relation implicit in characterizations of God as omniscient), and on the preservation of objective truth-values for theistic statements. Preserving objective truth-values is crucial for the theist in order to avoid a whole range of undesirable interpretations of theistic discourse, such as non-cognitivism (according to which theistic statements do not express genuine propositions at all); error-theory (according to which theistic statements do express genuine, though universally false, propositions); and subjectivism (according to which the truthvalues of theistic statements are determined by the attitudes or conventions of religious people). A structuralist reading of theism achieves exactly that: it preserves objective truth-values for theistic statements while remaining neutral on the question of ontology.

\footnotetext{
${ }^{3}$ John Cottingham, 'Transcending Science', this volume.

${ }^{4}$ This strategy has recently been defended by Fiona Ellis in her God, Value, and Nature (OUP, 2014). She argues that (a) there is a way to expand philosophical naturalism in such a way that it becomes compatible with theism, and that (b) this way is already implicit in the concept of a particular reading of naturalism.

${ }^{5}$ There are different forms of naturalism. 'Scientific naturalists' are convinced that every aspect of reality can be explained by the methods of the natural sciences. 'Expansive naturalists' concede that there are aspects of reality, such as human values and moral facts, which cannot be understood in terms of physical facts alone. See Ellis 2015 for a detailed discussion of these different kinds of naturalism, and their respective ability to accommodate theism. My account is compatible with all forms of naturalism.
} 
Cashing out theism in structuralist terms may not accommodate everything the theist was hoping for. In particular, my account doesn't offer an argument for the existence of God, but only for the possibility of the existence of God as characterized by our relations with him. I think that showing the possibility of God's existence may be the best thing a theist can hope for. However, I don't think that this is a trivial result at all. To the contrary, it constitutes a straightforward refutation of the view, implicit in most forms of naturalism, that scientific evidence seems to imply the impossibility of the existence of God. Arguing for the possibility of God's existence and objective truth-values for theistic statements in entirely naturalistic terms constitutes a genuine step forward, towards an interpretation of theism that is compatible with naturalism. Moreover, due to its ontological neutrality, a structuralist account of theism provides a discursive basis for the theism - atheism debate, thus enabling a discourse that would otherwise be impossible. As a consequence, it allows theism to reclaim centre-stage in the philosophical arena.

\section{Companions in Guilt}

Mathematical realists and theists are companions in guilt. Their guilt consists in a stubborn conviction of the existence of entities $\mathrm{E}$ with the following properties:

1. E's are not spatiotemporal

2. E's exist independently of our minds and language

3. empirical science neither implies the existence nor the non-existence of E's

4. statements about E's have truth-conditions and truth-values

5. truths about E's are objectively true

6. truths about E's are not reducible to truths about something else

7. it is possible for us human beings to attain truths about E's.

Mathematical realists believe in many such entities: numbers, sets, functions, and so forth. Theists believe in only one-God. Since it seems much more difficult to explain and justify belief in the existence of entities like E than in, say, tables, chairs, and beer mugs, mathematical realists and theists also face identical philosophical problems: first, how to explain the ontology of E's and thus, the semantics of E-truths, and second, how to account for our knowledge of E-truths.

For theists, investigating the ontology of God means trying to figure out the fundamental properties of God (omniscience? omnipotence? immateriality?). For mathematical realists, investigating the ontology of mathematics means trying to figure out the fundamental properties of numbers and other mathematical objects (are they best characterized in terms of sets? categories? structures?). Each of the many ontological stories we can tell about what numbers really are, and what God really is, then gives rise to a corresponding epistemological question: how do we acquire knowledge, on this or that particular ontological reading, of the truths about God and mathematical objects respectively? 
These are difficult questions, and so it is not surprising that, just like there is a great deal of disagreement among theists, there is a great deal of disagreement between mathematical realists. As John Bell and Geoffrey Hellman, two eminent philosophers of mathematics, put it:

"Contrary to the popular (mis)conception of mathematics as a cutand-dried body of universally agreed-on truths and methods, as soon as one examines the foundations of mathematics, one encounters divergences of viewpoint and failures of communication that can easily remind one of religious, schismatic controversy." (Bell and Hellman 2006: 64)

For example, just like theists disagree on how God is best characterized, and consequently, what the fundamental truths about God are, mathematicians disagree on what the correct way of axiomatizing set theory is (with or without the Axiom of Choice, the Axiom of Regularity, and higher-cardinal extensions?); whether set theory or category theory is the ultimate foundation of mathematics; and what the correct logical rules for mathematical proofs are ${ }^{6}$ Since it is not clear that disagreements like these will be ever be settled conclusively, it would be a problem if our evaluations of mathematical realism and theism respectively depended on agreement about questions of ontology. Fortunately, however, they don't.

In the philosophy of mathematics, adopting a structuralist view of mathematics has become a popular way of avoiding entanglement in ontological questions, while at the same time preserving what the mathematician is most concerned about, namely, (1) definite truth-values for mathematical statements combined with (2) a plausible story for how mathematical knowledge is possible. In the following, I will briefly explain the core points and merits of a structuralist philosophy of mathematics. I will then outline what a structuralist approach to theism could look like, and what the merits of such an account would be.

\section{A Structuralist View of Mathematics}

Structuralist positions in the philosophy of mathematics emerged in the second half of the $20^{\text {th }}$ century as a way to offer a middle-ground between Platonist (i.e. robust realist) and nominalist philosophies of mathematics. Very roughly, mathematical Platonists hold that mathematical objects (such as numbers or sets) exist independently of us, our linguistic conventions, our practices, etc., whereas mathematical nominalists believe that mathematical objects do not exist (at least not independently of us, our linguistic conventions, our practices, etc.). Platonists explain mathematical semantics and ontology in a straightforward way (mathematical statements refer to, and are true in virtue of, the existence of abstract mathematical objects), but have trouble explaining the epistemology of mathematics (how do we acquire knowledge of those objects, given that they are abstract, causally inert, and non-spatiotemporal?). Nominalists, on the other hand, can tell a straightforward story about mathematical epistemology (we have knowledge of mathematics because we "invented" it as a language to simplify and systematize cardinality assertions about the physical

${ }^{6}$ Cf. Bell and Hellman 2006; Feferman et al. 2000 
world), but have a hard time explaining mathematical semantics and ontology (if there are no mathematical objects, what do mathematical statements refer to, and what exactly makes them true?) ${ }^{7}$

Structuralists about mathematics share the nominalist intuition that simply postulating the existence of mathematical objects is contentious, yet agree with Platonists that mathematical statements do have objective, non-vacuous, mindindependent truth-conditions. There are several different forms of mathematical structuralism ${ }^{8}$ but the form that carries least ontological weight is modal structuralism, which was developed by Geoffrey Hellman $(1989 ; 1990)$. Its core idea is that, in order to explain (a) why mathematical statements are objectively true and (b) how we acquire mathematical knowledge, it is not necessary to commit ourselves ontologically. All that is required is a plausible story about (and thus, a commitment to) the possibility of the existence of mathematical structures. The following sections summarize that story.

\subsection{Mathematical Ontology}

What is the subject matter of mathematics? Platonists believe that it involves mind-independent abstract objects, each of which has a number of properties uniquely characterizing its intrinsic nature. Structuralists about mathematics, on the other hand, argue that mathematicians are in no position to commit themselves to the existence of such objects. This is not only because it would be impossible to explain how we acquire knowledge of them, but also because there are different, mutually exclusive ways of characterizing them, so that the idea of a unique, intrinsic nature for each mathematical object becomes untenable.

For example, following the work of a group of French mathematicians working under the pen name 'Nicolas Bourbaki' ${ }^{9}$ it is now widely accepted that all of mathematics (numbers, relations, functions, theorems) can be reduced to, or formulated in, the language of set theory. However, it is indeterminate to which sets exactly, say, the number three reduces: it can be expressed as $\{\{\{\emptyset\}\}\}$ (this reduction was suggested by Ernst Zermelo) or as $\{\emptyset,\{\emptyset\},\{\emptyset,\{\emptyset\}\}\}$ (this reduction was suggested by John von Neumann). These two different characterizations of the number three are not simply different ways of saying the same thing - because they have incompatible consequences. For example, von Neumann's reduction entails that the number one is a member of the number three, whereas on Zermelo's reduction, the number one is not a member of the number three. So every possible choice in characterizing the number three in terms of a set of sets will entail further, often mutually exclusive conceptual and ontological commitments. Consequently, the choice between different set-theoretic characterizations of the number three is far from trivial 10 And since we don't know of any way to settle the question of which sets 'lie at the foundation' or uniquely characterize the number three, the mathematical Platonist who wishes

\footnotetext{
${ }^{7}$ Benacerraf (1973) was the first to explicitly formulate this trade-off between Platonism and nominalism.

${ }^{8}$ For an overview of their main differences, see, for example, Reck and Price 2000 and Hellman 2005.

${ }^{9}$ See, for example, N. Bourbaki. 2004. Elements of Mathematics I: Theory of Sets. Berlin: Springer.

${ }^{10}$ This problem, now known as the Identification Problem, was first formulated by Paul Benacerraf (1965).
} 
to argue for the existence of uniquely characterizable mathematical objects is left with a seemingly insurmountable problem.

Note the similarity of this case of mathematical disagreement to some of the classical disagreements between theists: should we comprehend God as unipersonal (as Jews believe) or triune (as Christians believe)? Defenders of both views are convinced to have good reasons for their view, yet God cannot be both unipersonal and triune at the same time. Similarly, while traditional theists believe that God intervenes in the human world, deists believe that God does not intervene - and of course, both claims cannot be true at the same time. In the absence of agreement on such problems, it is indeterminate which attributes 'lie at the foundation' or uniquely characterize God-a serious problem for the theist who wishes to argue for the existence of a uniquely characterizable God.

Back to mathematics. Mathematical structuralists hold that, in light of such problems of indeterminacy, it is pointless to continue puzzling about unique characterizations for mathematical objects in terms of other mathematical objects. Rather, the mathematical structuralist argues, we should focus on the relations that hold between mathematical objects, and use those for an implicit characterization of mathematical objects.

Let's stick to the example of the natural numbers. Instead of wondering what the correct set-theoretic reduction of the number three is, mathematical structuralists suggest that we focus on the properties of the natural-numberstructure, i.e. "the pattern common to any infinite collection of objects that has a successor relation, a unique initial object, and satisfies the induction principle" (Shapiro 2000: 258). On this view, the subject matter of arithmetic is not a collection of mathematical objects (the natural numbers), but a single abstract structure, call it $S^{N}$, with the following properties:

1. $S^{N}$ has a unique initial object,

2. all objects in $S^{N}$ have a unique successor, and

3. all objects in $S^{N}$ satisfy the induction principle, such that, if a statement $\mathrm{p}$ is true of $\mathrm{n}$, then it is also true of $\mathrm{n}+1$.

On this characterization of the natural-number-structure, the number three is thus implicitly defined as the third position within that structure.

Compare this way of thinking about mathematics to the way in which we understand a game like chess. It is true that each chess piece has a particular shape: the king has a little cross on its top, the queen a little crown, each pawn a little sphere, etc. However, when we play chess, we abstract from the particular features of the pieces and focus solely on those that matter for the game, namely, the possible moves each piece can make on the chessboard in relation to the other pieces. In this sense, the game of chess is fully determined by its 'structure', which consists in (all configurations of) the spatial and 'possible moves' relationships that obtain between the pieces. The intrinsic features of the chess pieces themselves, on the other hand, (their material, shape, or colour) are completely irrelevant for the game - the pieces are mere reference points for the spatial and 'possible moves' relations ${ }^{11}$

\footnotetext{
${ }^{11}$ The chess analogy is Shapiro's (2000: 260ff).
} 
In the same way, the mathematical structuralist argues, the subject matter of mathematics is not determined by mathematical objects with intrinsic properties, but by a network of relations holding between mere positions, or points of reference, thus constituting a manifold of different structures. This view does not only sidestep difficult questions about the ontology of mathematical objects by focusing solely on the relations that hold between them. It also reflects a crucial fact about mathematical practice, viz. that mathematical progress consists in discovering new interrelations between, and not new intrinsic features of, mathematical objects.

\subsection{Mathematical Semantics}

The second question for the mathematical structuralist concerns semantics: do mathematical statements have definite truth-values, and if so, what is it that makes mathematical statements true? Clearly, the mathematical structuralist cannot hold that mathematical statements like ' $2+2=4$ ' are made true by anything like Platonic mathematical objects - reference to Platonic objects whose identity and existence are difficult or even impossible to determine, and knowledge of which seems inexplicable on a realist picture, is precisely what the structuralist wants to avoid. Rather, the structuralist provides a modal semantics for mathematical statements, i.e. a way of explaining the truth of mathematical statements purely in terms of logical possibility.

Take, for example, any arithmetical statement A, such as ' $2+2=4$ '. The structures constituting the subject matter of arithmetical statements are progressions (what the mathematician calls ' $\omega$-sequences'). The modal structuralist 'translation' of a statement like ' $2+2=4$ ' has two parts. The first part is hypothetical: it says that, if there were a structure $S^{N}$ satisfying the natural-numberrequirements ${ }^{12}$, then A would hold in $S^{N}$ (Hellman 1989: 16ff). The second part of the modal-structuralist interpretation of $\mathrm{A}$ is categorical: it asserts that it is logically possible for there to be structures satisfying the natural-numberrequirements (Hellman 1989: 24ff). Slightly more formally, the two components of the modal-structuralist interpretation of a simple arithmetical sentence A consists of the following two parts:

Hypothetical: $\square \forall S^{N}$ ( $S^{N}$ is a structure satisfying the natural-number-requirements $\rightarrow$ A holds in $S^{N}$ )

Categorical: $\diamond \exists S^{N}$ ( $S^{N}$ is a structure satisfying the natural-number-requirements)

The hypothetical component is relatively innocent: it does nothing but provide a translation pattern according to which statements in mathematical language (in our case: a statement of arithmetic) are converted into statements

\footnotetext{
${ }^{12}$ What I call the 'natural-number-requirements' here are essentially the axioms of Peanoarithmetic: $0 \in \mathbb{N}$ ('Zero is a natural number'); $\mathrm{n} \in \mathbb{N} \Rightarrow n^{\prime} \in \mathbb{N}$ ('Every natural number $\mathrm{n}$ has a successor n' which is a natural number'); $\mathrm{n} \in \mathbb{N} \Rightarrow n^{\prime} \neq 0$ ('Zero is not the successor of a natural number'); $\mathrm{m}, \mathrm{n} \in \mathbb{N} \Rightarrow\left(m^{\prime}=n^{\prime} \Rightarrow m=n\right)$ ('Natural numbers which have the same successor are identical'); $0 \in X \wedge \forall n \in \mathbb{N}:\left(n \in X \Rightarrow n^{\prime} \in X\right) \Rightarrow \mathbb{N} \subseteq X$ ('If X contains the number zero, and with every natural number $\mathrm{n}$ also its successor $\mathrm{n}$ ', then the natural numbers are a subset of $\mathrm{X}^{\prime}$ ).
} 
of second-order modal logic ${ }^{13}$ The categorical component, however, is less innocent: it asserts the logical possibility of the relevant structures (in our case: the natural-number structure) ${ }^{14}$ To be justified, this assertion must be derived from uncontroversial facts, and the way Hellman achieves this is by inviting us to imagine any kind of mark, for example a brush stroke, plus a constructive rule for generating infinitely many 'next marks':

"Let ' $\mathrm{A}(\mathrm{x}, \mathrm{y})$ ' mean ' $\mathrm{y}$ is generated after $\mathrm{x}$ in accordance with rule $\mathrm{R}$ ', and consider the sentence, $\exists x \exists y A(x, y)$ \& ' $\mathrm{A}$ is asymmetric and transitive' \& $\forall x \exists y A(x, y)$ \& $\forall x \exists ! y(A(x, y)$ \& $\neg \exists z(A(x, y) \& A(z, y)) \ldots$ Now this may not in fact hold in the real world, but I can see no reason why it should not be logically possible (much as classical Newtonian models of infinitely extended space or time are possible)." (Hellman 1990: 317)

In other words, Hellman argues that it is physically (and thus logically) possible for there to be an initial brush stroke plus a rule for creating additional brush strokes, and that it is logically possible to apply this rule an infinite number of times, thus creating an infinite sequence of brush strokes. But if an infinite sequence of brush strokes is logically possible, then (given that an infinite sequence of brush strokes exemplifies the natural-number structure) the naturalnumber structure is also logically possible - just like the categorical component asserts.

The modal-structural interpretation of a mathematical statement like ' $2+2=4$ ' thus involves no commitment to the actual existence of mathematical structures, but only to their logical possibility. The modal structuralist has thus presented a semantics for mathematical statements that comes at no ontological cost, yet preserves what the mathematician is most concerned about, namely objective truth-values for mathematical statements. Note that the modal-structural translation scheme nevertheless involves no explicit rejection of mathematical ontology: for all that has been said, mathematical objects might in fact exist.

Modal structuralism is thus a position that avoids interpreting mathematics in ontologically committal terms, but that clearly embraces truth-value realism for mathematical discourse. As such, it is a position that is silent on, but fully compatible with, ontological commitment. We can think of the modal structuralist as someone who sidesteps questions of ontology by extracting the nominalistic (i.e. ontologically neutral) content from mathematical assertions in order to provide a minimal semantics for mathematical discourse. The introduction of modal operators preserves verbal agreement with the Platonist and thus, enables a meaningful exchange between Platonists and nominalists. This is an important point to note with regard to the following sections, where we will investigate the possibility of providing a modal-structuralist translation scheme for theistic assertions.

\footnotetext{
${ }^{13}$ I say 'relatively' innocent because not everyone considers second-order (modal) logic ontologically innocent, given that it seems to imply a commitment to universals.

${ }^{14}$ Without the categorical component, modal structuralism would be indistinguishable from ordinary 'if-then-ism', or fictionalism, about mathematics, and would inherit the latter's major problem of vacuous truth. Just like 'if-then-ism' about mathematical objects renders all mathematical sentences true if in fact no mathematical objects exist-because conditionals with false antecedents $(\mathrm{F} \rightarrow \mathrm{T})$ are always vacuously true- - a modal 'if-then-ism' about mathematical structures would render all mathematical sentences true if the relevant mathematical structures are impossible (cf. Hellman 1990: 316).
} 


\subsection{Mathematical Knowledge}

Finally, a modal-structural interpretation of mathematical statements offers a straightforward explanation of how we acquire knowledge of mathematical structures: (i) we perceive objects or constellations in the concrete world that exemplify a portion of the natural-number-structure (for example, a sequence of brush strokes or a line of trinkets in a row); (ii) we then abstract from the intrinsic features of the brush strokes or trinkets and zoom in on the structural relations holding between them; finally, (iii) we generalize these relations into a purely structural picture. In this way, our knowledge of mathematical structures is a direct consequence of our perception of concrete structured objects and constellations in the physical world, combined with our ability to abstract from particular intrinsic features and to generalize structural relations. Take again the number three for example. Given that the natural-number-structure is exemplified by countless collections in the physical world-for example sequences of brush strokes or trinkets - the mathematical structuralist has no difficulty explaining how we come to have knowledge of the natural-number-structure and specific 'positions' in that structure: we perceive instances of it everywhere around us. Consequently, we also perceive instances of the third position of the natural number structure, which we commonly refer to as the number three. Let's now turn to see whether we can construct a structuralist picture of theism that is equally philosophically advantageous.

\section{A Structuralist View of Theism}

What does all of this mathematical talk have to do with theism? Just like it is nonsense, from the structuralist point of view, to consider a mathematical object like the number three in isolation from its relations to other mathematical objects, it is, I submit, nonsensical to think of God in isolation from God's relations to the world and all other beings. A modal structuralist account of theism accommodates the atheist's intuition that simply postulating the existence of a supreme yet imperceptible, causally inert being is philosophically contentious. At the same time, my account provides a way to substantiate the theist's conviction that theistic statements have objective, non-vacuous, mind-independent truth-conditions under which the assertion that God exists is true.

Consider again the chess analogy: can we meaningfully imagine a chess piece, for example one that plays the role of a rook, independently of a chess game? No, we cannot. This is because, in the absence of other pieces, a chessboard, and two players, we wouldn't know how to think about its moves, its position, etc. In other words, we can only comprehend a chess piece like the rook in conjunction with all other constituents of the game, just like we can only understand the number three in relation to the rest of the natural-numbers-structure. A structuralist view of theism formulates the exact same intuition for the case of God.

\subsection{Theistic Ontology}

What is the subject matter of theology? God, of course. However, it is not at all clear what we mean by that term. For example, theists disagree strongly on which properties exactly characterize God's nature (is God omnipotent? simple? 
immutable?), and indeed, on whether God can be analyzed in terms of necessary and sufficient conditions at all. 15

The view I propose acknowledges such disputes as potentially unresolvable. Instead of demanding ontological commitment to a supreme being whose nature can, and has been, defined in a number of mutually exclusive ways, structuralist theists suggest that we focus on the structure of theism - the structure composed of the relations in which we stand to God. My account thus aims to be a response to the question what God is for us, rather than to the question what God is in essence.

Focusing on the relations between God and its creatures rather than on definitional aspects not only avoids problems of indeterminacy, but also reflects the fact that it is in virtue of those relations rather than in virtue of definitions that most theists initially come to believe in God. For instance, many theists would agree that love, contemplation, and prayer are prime examples for relations rooted in, and therefore leading to, God. Others consider awe, submission, and even fear to be the characteristic features of their relationship with God. And yet others think that it is primarily through joy, gratefulness, and praise that we relate to God.

Every theist thus has her own, individual relationship with God. However, there are three basic relations that are arguably implicit in all of them. It is these three relations that, according to my account, implicitly define theism. The first one captures the fact that all religious concepts defining a theist's life derive from the assumption of there being a God in the first place. For example, an action cannot be sinful without there being a God who defines which actions constitute sins. This is to say that, before there can be any theistic concept at all, there must be God. Without God, religious concepts are meaningless. Let's call this very basic relation the relation of logical priority: God is logically prior to all theistic, and possibly to all religious concepts that determine a theist's beliefs and actions. The second basic relation captures the fact that all religious concepts defining a theist's life derive from the assumption that God's existence is fundamental to all other objects and beings, whose existence is consequently dependent on and grounded in God's existence. Let's call this the relation of metaphysical priority: God is metaphysically prior to all creatures. This relation is implicit in the story of creation; in characterizations of God as all-powerful; in the belief that God resurrects the dead; in principles concerning the right way to worship God and to live one's life, etc. It is arguably also a relation in which further relations such as awe and submission, love and contemplation are rooted. The third basic relation that arguably characterizes every theist's relationship with God is that God's knowledge is superior to the knowledge of every other being. In particular, God knows everything that every being thinks and does at all times, so that it is not possible to ever think or do something without God

\footnotetext{
${ }^{15}$ Already Aquinas (Summa Theologiae, 1a, 3-11) and Maimonides (Guide for the Perplexed, 1.51) were sceptical of the idea that God's nature can be captured in terms of a list of divine attributes, and a number of contemporary philosophers of religion defend related viewpoints. Howard Wettstein (2012), for example, argues that the focus of contemporary philosophy of religion on conceptual analysis ignores and thus obscures the fact that religious scriptures tend to promote a purely affective, emotion-based approach to religious practice, not a commitment to firm metaphysical beliefs. Relatedly, Fiona Ellis (2017) rejects a philosophy of religion based entirely on conceptual analysis, and suggest a praxis-oriented approach that reflects the reality of religious life rather than obsessing over necessary and sufficient conditions for religious concepts. See also Kyle Scott's contribution to this volume.
} 
knowing it. Let's call this relation between God and all other beings the relation of epistemic superiority: God is epistemically superior to all creatures. This relation is implicit in all principles of religious ethics and morality (which are grounded in the belief that God know who acts right and who acts wrong), most notably in in the belief that God rewards the righteous and punishes evildoers. As indicated above, there are certainly many more relations that characterize a theist's relationship with God, but these are arguably the three fundamental one's: the logical and metaphysical priority as well as the epistemic superiority of God over all other objects, beings, and their actions.

There are certainly many more features that characterize a theist's relationship with God, but these are, I submit, the three fundamental ones: the logical, metaphysical, and epistemic priority of God over all other objects, beings, and their actions.

Now, just as in the case of numbers and in the case of chess, we can picture the structure of theism as determined by the relations between a central position, commonly referred to as 'God', and infinitely many other positions (referred to as beings, objects, etc.). The central position stands in a relation of logical, metaphysical, and epistemic priority to the all other positions, which, in turn, stand in countless relations to one another. On this picture, the structure of theism, call it $S^{T}$, can be described as follows:

1. $S^{T}$ is a structure holding between infinitely many objects and beings that stand in relations of logical, metaphysical, and epistemic priority to one another,

2. $S^{T}$ has a unique, central object $\mathrm{G}$ (conventionally referred to as 'God'), such that

3. G is logically prior to all objects and beings of $S^{T}$,

4. G is metaphysically prior to all objects and beings of $S^{T}$, and

5. G is epistemically superior (prior) to all objects and beings of $S^{T}$.

God, on this picture, is implicitly defined as the central point of reference in the theism-structure, which is in turn defined solely in terms of logical, metaphysical, and epistemic priority relations. Unlike all other objects and beings, God is unique in that She is the only being that is prior in all three respects to all other objects and beings.

Again, we can compare this way of thinking to the way in which we understand a game of chess and the roles of each chess piece. Just like we do not need to know anything about the intrinsic features of the chess pieces (their material, colour, or shape) in order to understand their role in the game and their meaning for one another, we do not need to know anything about the intrinsic features of God in order to understand Her role as the central point of reference in the theism structure, and Her meaning for all other 'positions', occupied by other beings, in this structure. God is thus fully determined by the structure of theism, which consists in (all configurations of) the logical, metaphysical, and epistemic priority relationships that hold between the central position of the structure, and all other positions. The intrinsic features of God (and consequently, of all other positions in the structure), on the other hand, are irrelevant in order to understand the structure of theism - as is the question whether or not god has any intrinsic features at all. 


\subsection{Theistic Semantics}

Just like in the case of mathematical realism, also in the case of theism there is one question that has particular importance: do theistic statements have objective truth-values, and if so, what is it that makes theistic statements true? Recall that the preservation of objective truth-values is crucial for all theists who want to avoid non-cognitivist, error-theoretic, or subjectivist interpretations of theistic assertions. The commitment to objective truth-values is thus essential for the theist. Consequently, the central question becomes: what is it that makes theistic statements true?

Clearly, the structuralist theist cannot hold that a theistic statement like 'God is omniscient' is made true by a uniquely characterizable object Godreference to such an object whose identity and existence are difficult or even impossible to determine, and knowledge of which can seem inexplicable on a realist picture, is precisely what the structuralist theist wants to avoid. Rather, the structuralist theist can provide a modal semantics for theistic statements, i.e. a way of explaining the truth of theistic statements purely in terms of logical possibility.

Take, for example, a theistic statement T, such as 'God is omniscient'. Just like in the case of mathematics, the modal-structuralist 'translation' of this statement has two parts. The first part is hypothetical. It says that, if there were a structure $S^{T}$ satisfying the theism-requirements, then T would hold in $S^{T}$. The second part is the categorical component of the modal-structuralist interpretation. It asserts that it is logically possible for there to be a structure satisfying the theism-requirements. Slightly more formally, the two components of the modal-structuralist interpretation of a theistic assertion like $\mathrm{T}$ are:

Hypothetical: $\square \forall S^{T}$ ( $S^{T}$ is a structure satisfying the theism-requirements $\rightarrow$ T holds in $S^{T}$ )

Categorical: $\diamond \exists S^{T}$ ( $S^{T}$ is a structure satisfying the theism-requirements)

The hypothetical component is metaphysically innocent: all it does is provide a translation pattern according to which statements in theistic language (in this case: a statement about God's omniscience) are converted into statements of second-order modal logic. As in the mathematical case, it is the categorical component that involves a substantial assertion. viz. the logical possibility of the structure in question. And just as in the case of mathematics, this categorical assertion must be derived from uncontroversial facts in order to be justified. What are these uncontroversial facts?

Recall that Hellman derives the logical possibility of the natural number structure from the physical possibility of there being an infinitely extendible series of brush strokes, generated by a repeated application of a constructive rule to an initial brush stroke. Put differently, Hellman argues that it is physically (and thus logically) possible for there to be an initial brush stroke plus a rule for creating additional brush strokes, and that it is logically possible to apply this rule an infinite number of times, thus creating an infinite sequence of brush strokes instantiating the natural-number structure.

Also in the case of theism, we can derive the logical possibility of a structure satisfying the theism requirements from uncontroversial facts about the physical world, combined with uncontroversial facts about counterfactual reasoning. We 
begin with the assertion that it is physically possible for there to be a being that is logically, metaphysically, and epistemically prior to another being in the sense described above. One example for this is the relation between mother and child. The concept of a child implies the concept of a mother; hence, the concept of a mother is logically prior to the concept of a child. Moreover, the existence of a mother is fundamental to the existence of a child, whose existence is, in turn, dependent on, or grounded in, her mother's existence. The mother is thus metaphysically prior to the child. Finally, at least up to a certain age, a mother's knowledge is clearly superior to that of her child; hence, she is epistemically superior to her child.

From the physical possibility of the mother-child structure, which is determined by relations of logical, metaphysical, and epistemic priority, we can infer the metaphysical possibility of a being that is logically, metaphysically, and epistemically priori to all beings in the physical world. How can we do that? Generally speaking, we are justified in asserting the metaphysical possibility of an object, being, or event just in case a counterfactual derivation of the assumption that this object, being, or event is possible does not yield a contradiction 16 The assumption of there existing a being that is logically, metaphysically, and epistemically prior to all other objects and beings does not yield a contradiction. Therefore, we are justified in asserting the metaphysical possibility of such a being, which, in turn, entails the logical possibility of this being. But if the existence of such a being is possible, then (given that the conjunction of this being and all other objects and beings exemplifies the theism structure) the theism structure is also logically possible - just like the categorical component asserts.

Note that this translation scheme of a sentence like 'God is omniscient' involves no commitment to the actual existence of the theism structure, but only to its logical possibility. Nevertheless, it involves no explicit rejection of theistic ontology: for all that has been said, God might exist. The modal structuralist has thus presented a semantics for theistic statements that comes at no ontological cost, yet preserves what the theist is most concerned about, namely objective truth-values for theistic statements.

Modal structuralism about theism is thus a position that avoids interpreting theism in ontologically committal terms, but that clearly embraces truth-value realism for theistic discourse. As such, it is a position that is silent on, but fully compatible with, ontological commitment to God. We can think of the modal structuralist theist as someone who sidesteps questions of ontology and extracts the nominalistic (i.e. ontologically neutral) content from theistic assertions, in order to provide a minimal semantics for theistic discourse. The introduction of modal operators preserves verbal agreement with the traditional theist and thus, enables a meaningful exchange between theists and atheists. By focusing on the nominalistic content of theistic assertions only, modal structuralism about theism thus vindicates theistic belief by making it a rationally defeasible option. It takes seriously both the concerns of the theist (by honouring the importance of providing definite truth-values for theistic statements) and the concerns of the atheist (by honouring the importance to refrain from ontological commitments).

\footnotetext{
${ }^{16}$ For a detailed discussion of the way in which we generate knowledge of metaphysical modality, see Williamson 2007: 134ff.
} 


\subsection{Theistic Knowledge}

Finally, just like in the case of mathematics, the advantage of characterizing God and theism in structuralist terms is not only that it avoids problems of indeterminacy by avoiding questions of ontology throughout. It also offers a straightforward explanation of how we acquire knowledge of the theism structure.

In the first step, we perceive constellations of beings in the concrete world that exemplify a portion of the theism structure ST. Recall the example of mother and child. The mother stands in a relation of logical and metaphysical priority, and epistemic superiority to her child. Thus, mother and child exemplify the theism structure. However, they exemplify it only partly. This is because, unlike God, the mother is not logically, metaphysically, and epistemically prior/ superior to all other beings. The theism-structure is thus only partially instantiated. Again, compare this case to the case of the natural numbers. The natural-number structure is exemplified by countless collections of objects (such as a sequence of trinkets in a row). However, the natural-number structure is only ever partially instantiated. After all, the natural-number structure is infinite, whereas no collection of objects in the physical world is. Hence, the natural-number structure can only ever be exemplified partially in the physical world.

However, these partial instantiations suffice to give us knowledge of the structure in its entirety. How so? In the second step, we abstract from the intrinsic features of the specific mother-and-child example, focusing only on the structural relations holding between them. In other words, we zoom in on the relations that hold between mother and child, while at the same time ignoring the two specific beings ('objects') instantiating these relations. We focus thus our attention solely on the set of the three relations: logical priority, metaphysical priority, epistemic superiority.

In the third step, we then generalize these relations into a purely structural picture of logical, metaphysical, and epistemic priority relations. From this purely structural picture, we finally derive the logical possibility of there being a constellation exemplifying the theism-structure in its entirety, i.e. of there being a structure with one central object, God, standing in logical, metaphysical, and epistemic priority/ superiority relations to all other objects and beings in the structure - the full structure of theism.

To sum up: just as we acquire knowledge of the natural-number structure by perceiving partial instantiations (e.g. sequences of brush strokes) of that structure in the physical world, and by generalizing that structure into a full picture of the structure, we acquire knowledge of the theism structure by perceiving partial instantiations of it (e.g. mother-child-relations) in the physical world, and by generalizing it into a full picture of the structure ${ }^{17}$ On this view, our knowledge of the logical possibility of the theism structure is thus a direct consequence of (1) our perception of constellations of physical objects or beings standing in logical, metaphysical, and epistemic priority/ superiority relations to one another, (2) our ability to abstract from particular objects or beings instantiating that structure, and to generalize structural relations, and (3) our

\footnotetext{
${ }^{17}$ Note that the partial instantiations of the theism-structure we perceive in the physical world also inform our way of talking about God: we refer to God as a 'father' or 'mother', to human beings as God's 'children', etc.).
} 
ability to derive, from uncontroversial assumptions, the logical possibility of there being a constellation exemplifying this structure.

\section{Conclusion}

This way of characterizing theism may seem very unconventional-perhaps too unconventional for a traditional theist who believes in God as uniquely characterized by traditional divine attributes such as omniscience, omnipotence, omnipresence, etc. However, it really is nothing but a formalized description of what I take to be the core of many religious people's beliefs: the experience of themselves as standing in a relationship to a being whose nature cannot be grasped conceptually, but whose relation to themselves is perfectly clear. The reason we may not be able to understand God's nature while at the same time having no doubt about our relationship to God is that, as constituents of this relation, we experience it first-hand and thereby generate an immediate, phenomenal knowledge of what it is like to stand in such a relation. We can illustrate this point by returning to the example of mother and child, who stand in relations of logical, metaphysical, and epistemic priority. While the child does probably not know everything about the nature of its mother (much less about the correct conceptual analysis of the concept 'mother' or 'motherhood'), it does understand the nature of its relation to its mother perfectly because it is a constituent of this relationship and thus, experiences it first-hand.

Just like we can say many more things with certainty about the way in which numbers relate to each other than we can say about the intrinsic nature of numbers, there are many more things we can say with certainty about the way in which we relate to God than we can say about the nature of God. Structuralist theism accommodates this fact by offering an interpretation of theistic assertions in terms of the logical possibility of structural relations between beings.

Consider further that nothing in this view prevents the theists from ascribing those properties to God in addition to the structuralist view. A structuralist view of theism extracts the shareable, nominalistic content from theistic assertions through its modal structuralist translation schema, and thus provides a minimal semantics for discourse about God. The introduction of modal operators preserves verbal agreement with the atheist and thus, enables a meaningful exchange between theists and atheists on the subject matter of the possibility of God and theism. This is already much more than what is granted by most scientific naturalists, who are convinced that science holds the "monopoly on reality and explanation" 18 and that theistic belief is consequently untenable ${ }^{19}$

A structuralist view of theism demonstrates the rational viability of theism in purely naturalistic terms. It does not offer a anything beyond that. In particular, it does not offer an argument for the existence of God. However, as the history of philosophy shows, it is not clear that God's existence could ever be proved or disproved by means of an argument. While traditional theists may find this view unacceptably deflated, it does achieve the goal of rendering theism

\footnotetext{
${ }^{18}$ Fiona Ellis, 'Religious Understanding and Theory'

${ }^{19}$ Note the similarity of this line of argument to the familiar Quinean view that we should be ontologically committed to all and only entities quantification over which is indispensable to our best scientific theories - the implication being, of course, that both the 'entity' God and truths about this entity are dispensable to the scientific project of explaining the phenomena of the world.
} 
compatible with naturalism. And perhaps showing that theism is possibly true is not as modest a result as it may first seem. To put it in Peter De Vries words, "It is the final proof of God's omnipotence that he need not exist in order to save us." 20

Word count including references and bibliography: 7,100.

\footnotetext{
${ }^{20}$ Peter De Vries, The Mackarel Plaza, 1958
} 


\section{References}

[1] Bell, John, and Hellman, Geoffrey. 2006. 'Pluralism and the Foundations of Mathematics.' In: Stephen Kellert, Helen Longino, and Kenneth Waters (eds.). Scientific Pluralism. Minnesota Studies in the Philosophy of Science. Minneapolis: University of Minnesota Press: 64-79.

[2] Benacerraf, Paul. 1973. 'Mathematical Truth.' Journal of Philosophy Vol. 60: 661-679.

[3] Ellis, Fiona. 2015. God, Value, and Nature. Oxford: Oxford University Press.

[4] Ellis, Fiona. 2017. 'Religious Understanding, Naturalism, and Desire.' In: Stephen Grimm (ed.). Making Sense of the World: New Essays on the Philosophy of Understanding. Oxford: Oxford University Press.

[5] Feferman, Solomon; Friedman Harvey; Maddy Penelope; Steel, John. 2000. 'Does Mathematics Need New Axioms?' The Bulletin of Symbolic Logic Vol. 6 No. 4: pp. 401-446.

[6] Hellman, Geoffrey. 1989. Mathematics without Numbers: Towards a ModalStructural Interpretation. New York: Oxford University Press.

[7] Hellman, Geoffrey. 1990. 'Modal-Structural Mathematics.' In: A.D. Irvine (ed.). Physicalism in Mathematics. Dordrecht: Kluwer Academic Publishers.

[8] Hellman, Geoffrey. 2005. 'Structuralism.' In: Stewart Shapiro (ed.). The Oxford Handbook of Philosophy of Mathematics and Logic. New York: Oxford University Press.

[9] Johnson, Dominic and Bering, Jesse. 2006. 'Hand of God, Mind of Man: Punishment and Cognition in the Evolution of Cooperation.' Evolutionary Psychology Vol. 4: 219-33.

[10] Reck, Erich, and Price, Michael. 2000. 'Structures and Structuralism in Contemporary Philosophy of Mathematics.' Synthese Vol. 125 No. 3: 341-383.

[11] Shapiro, Stewart. 2000. Thinking About Mathematics. New York: Oxford University Press.

[12] Williams, Rowan. 2002. 'The deflections of desire: negative theology in trinitarian disclosure.' In: Oliver Davies and Denys Turner. Silence and the Word: Negative Theology and Incarnation. Cambridge: Cambridge University Press.

[13] Williamson, Timothy. 2007. The Philosophy of Philosophy. Oxford: Blackwell Publishing. 